\title{
DESENVOLVIMENTO DO APLICATIVO PARA O CALCULO DA MASSA CORPORAL DE CRIANÇAS E SUA APLICAÇÃO EM UM PROJETO REAL
}

\author{
Heloyza Kethylin Ribeiro Alves, (UFCG), heloyzakethylin@hotmail.com \\ Cecir Barbosa de Almeida Farias, (UFCG), cecir.almeida@gmail.com
}

\section{Resumo}

As crianças devem ser estimuladas a fazer atividades físicas diariamente, de preferência ao ar livre ou em ambiente propício para tal. Esta prática de atividade desde a infância estimula a criação de hábitos saudáveis, reduz o risco de obesidade e de doenças tais como: diabetes, hipertensão e alguns tipos de câncer, ela propicia interação social e benefícios psicológicos, gerando uma ampla melhora na qualidade de vida. O judô é um esporte que pode ser utilizado e tem uma grande aceitação nas escolas e academias. Ele se tornou um dos esportes mais praticados por crianças e adultos e teve um aumento significativo no número de praticantes. A sua prática é de suma importância por crianças, pois grandes atletas começam desde cedo neste esporte. Porém, para a prática de esportes, é necessária a realização de consulta médica prévia e também de consultas regulares nas crianças, para identificar patologias que possam restringir determinados tipos de exercícios. Quando não há esse acompanhamento, podem acontecer complicações que afastem as crianças dos exercícios. Este trabalho apresenta um aplicativo chamado "IMC para Crianças" criado para obter o valor do cálculo do IMC - Índice de Massa Corpórea de crianças, a fim de obter um resultado imediato, através do uso de celular, o qual poderá ser avaliado pelos instrutores dos esportes e pelos pais das crianças.

Palavras-chaves: Aplicativo móvel, Saúde, Atividade física, Judô.

\section{Introdução}

Estamos nos preparando para lidar com a velocidade em que ocorrem as transformações na sociedade. As pessoas podem estar conectadas 24 horas por dia e acompanhar em tempo real tudo que ocorre ao seu lado e também do outro lado do mundo. A tecnologia e a inovação são dois itens que proporcionam evolução e revolução. Chegamos na era digital, em que as informações transitam em velocidade instantânea e há comunicação direta entre as pessoas, sem 
limites de tempo e espaço, estamos falando na quarta revolução industrial e na indústria 4.0. (Ferreira, 2017)

O blog Nova Escola (2016) firma que: “O ensino de programação para crianças e adolescentes tem crescido exponencialmente no Brasil e no mundo. Além do surgimento de escolas especializadas, muitos colégios têm a proposta em suas atividades curriculares. $\mathrm{O}$ ensino de programação é importante porque estimula a criatividade, a autonomia e desenvolve o raciocínio lógico e a capacidade de resolução de problemas e trabalho em equipe, habilidades muito valorizadas no século 21."

A programação pode estar presente no ensino de diversas formas, como no auxílio das disciplinas como português e matemática, podendo explorar ainda diversos temas. Nova escola (2016) afirma que independentemente da forma, o importante é que o ensino de programação nas escolas não seja visto como fim em si mesmo, mas como uma nova forma de expressão e principalmente, como uma maneira de aumentar a aproximação e o envolvimento do aluno com o conhecimento.

A programação em sua composição curricular é composta por diversas linguagens sendo elas o Java, Python, C\#, PHP, C++, C, Programação em Blocos, entre outros. Diante dessas linguagens, a linguagem em blocos é a mais fácil de compreender e aprender devido ao seu manuseio poder ser realizado através de figuras e imagens de pequenas partes encaixáveis, assim como imagens de um quebra-cabeças, tipo de jogo utilizado em brincadeiras infantis.

"A programação em blocos nada mais é do que uma metodologia para o ensino de conceitos ligados a programação, desenvolvimento de softwares/aplicativos e lógica de uma forma geral. Esse paradigma surgiu para auxiliar na transmissão de um conhecimento puramente abstrato para algo mais "sólido", ou que lembrasse um pouco do cotidiano, principalmente de crianças e adolescentes." (Nova Escola, 2016). A inspiração foram os brinquedos da marca LEGO, que se conectam entre si podendo formar variadas estruturas.

Para a aplicação da programação dentro de sala de aula, durante as atividades do projeto, se fez necessário o uso dessa linguagem, devido ao melhor entendimento e possibilidade de programação pelos alunos

Diante disto, esta linguagem foi escolhida para ser utilizada em um Projeto de Extensão intitulado "Inclusão Digital através da prática da lógica e da programação para alunos da rede pública da cidade de Sumé, PB” o qual é vinculado ao PROBEX da Universidade Federal de 
Campina Grande. Seis alunos da UFCG, participantes da equipe do projeto no campus CDSA - Centro de Desenvolvimento Sustentável do Semiárido, criaram juntamente com a professora orientadora do projeto, um material didático e vários aplicativos para celular na ferramenta MIT App Inventor (MIT, 2012) e dentre eles, é apresentado aqui, o aplicativo "IMC para Crianças" criado para obtenção do valor do índice de Massa Corpórea de crianças, o qual foi utilizado com crianças que são atletas de Judô, no projeto de extensão, também vinculado ao PROBEX da UFCG intitulado "PROCARIRI" cujo objetivo é desenvolver a prática do esporte com os jovens da cidade.

\section{Referencial teórico}

"Mudar é preciso, sendo imprescindível estarmos preparados para lidar com a velocidade em que ocorrem as transformações na sociedade. É algo surpreendente e sem precedentes o quanto mudamos na forma de comunicar, relacionar, produzir, consumir e se informar" (Ferreira, 2017) Podemos perceber isso no mundo do trabalho, no consumo e nos hábitos da população, onde podemos pedir uma refeição, um transporte, fazer uma compra, uma transferência bancária e realizar uma reunião - tudo através dos aplicativos de celular.

Por muito tempo temia-se o avanço tecnológico e não existia a noção de onde se poderia chegar. Falava-se em substituir o homem pela máquina, mas o que podemos perceber é que houve uma integração entre eles. "O maior patrimônio das empresas é seu capital intelectual e de seus colaboradores. O ser humano, principalmente dotado de conhecimento, será sempre necessário na concepção de produtos, serviços e na interface com a máquina.” (Ferreira, 2017)

De fato, ao utilizar a internet para fazer uma compra, uma pesquisa ou realizar atividades em sala de aula o ser humano facilita e otimiza o período que será gasto nessa tarefa. Para todas as pessoas há um aproveitamento melhor do tempo e, obviamente, a eficácia do trabalho. "São inúmeras as maneiras de conseguir conhecimento nas ferramentas ou aplicativos digitais, além da agilidade na comunicação que, sem dúvidas, agrada os jovens, já que tudo para eles precisa acontecer de forma rápida.” (SIMULARE, 2019)

\subsection{O judô como atividade física para crianças}

Praticar atividade física é imprescindível para todos aqueles que buscam ter uma vida saudável e equilibrada, mesmo que o foco não seja estético. Elas estimulam a oxigenação do corpo, 
melhoram o metabolismo do nosso organismo, promovem o desenvolvimento dos músculos e do condicionamento físico, emagrecem e, com toda certeza, são responsáveis pelo bem-estar e uma considerável sensação de prazer. Porém, nem todo mundo gosta da atividade física oferecida por academias, como levantamento de peso, ou da rotina dos centros de musculação. E é aí que entra a luta. Seja qual for a modalidade, essa é uma prática que pode ser feita por pessoas de todas as idades, independentemente de gênero e condição física. (Sardinha Evolution,2017)

No blog da Saúde (2016), Aline Czezacki afirma que: "Além da contribuição no aspecto individual que a modalidade proporciona, o Judô ajuda milhares de crianças e adolescentes em situação de vulnerabilidade social no Brasil, contribuindo para melhorar o aspecto de inclusão social do país através do incentivo ao esporte. Um exemplo de projeto realizado no país é o Avança Judô, da Confederação Brasileira de Judô (CBJ).

Desde 2007, ele atua na "criação de condições e oportunidades para que todas as crianças e adolescentes em situação de vulnerabilidade social possam desenvolver, através do esporte, o potencial como pessoas e cidadãos". Atualmente são atendidas no projeto 2.574 crianças e adolescentes de sete a 16 anos em 14 estados brasileiros" (Aline Czezacki, 2016)

\subsection{Desenvolvimento de aplicativos}

Com o crescimento do mercado e os altos investimentos no setor de aplicativos, produzir um app tem ficado cada vez mais comum. Além da facilidade e agilidade que os apps oferecem, segundo uma pesquisa 95\% do mundo utiliza aplicativos como o WhatsApp, por exemplo. Se está em seus planos o desenvolvimento de um aplicativo, é necessário então entender como essa logística funciona (Gabellini, 2018). Com isso disciplinas cursadas na área de engenharia, estudantes podem desenvolver aplicativos através das linguagens de programação. Mas tudo isso não pode prejudicar o aprendizado e ser empecilho para o estudo e prática da programação para celular.

Seja você um atleta ou uma pessoa que pratica esportes raramente, deve concordar que a tecnologia tem ajudado (e muito) a incentivar as pessoas a serem mais ativas. Muitos culpam a internet e os aparelhos eletrônicos pelo aumento do sedentarismo no mundo, mas a verdade é que esses aparatos também ajudam as pessoas a se exercitarem, graças ao desenvolvimento de aplicativos para atividades físicas. Essas ferramentas são aliadas da saúde e da qualidade de vida, pois auxiliam a monitorar os movimentos do corpo, registram o gasto e consumo de 
calorias, enviam alertas para disciplinar a ingestão de líquidos e até mesmo ajudam a montar grupos de corrida e caminhada nas ruas (Machado,2018).

Além do fato de que aplicativos são mais fáceis de serem conhecidos, obtidos e instalados pela sociedade, devido a facilidade de divulgação nas lojas virtuais. Porém o aprendizado da programação, requer uma série de conhecimentos e dedicação nos estudos, problema que pode ser solucionado através da realização de cursos e aulas nas escolas públicas ou privadas, desde o ensino fundamental.

\section{Metodologia}

Para o desenvolvimento do aplicativo apresentado neste estudo foram realizadas consultas em artigos, livros, revistas, e-books e principalmente no material didático criado no projeto de extensão "Inclusão Digital através da prática da lógica e da programação para alunos da rede pública da cidade de Sumé, PB", a fim de obter informações e criar o aplicativo de "IMC para Crianças".

Foi desenvolvido então o aplicativo citado na ferramenta APP Inventor (MIT 2012) conforme apresentado na Figura 1 para o cálculo da massa corporal de crianças na faixa de 0 - 10 anos, com o intuito de proporcionar o cálculo imediato do índice de Massa Corpórea - IMC de crianças e verificar o resultado imediatamente no aplicativo gerado no celular utilizado. Em seguida, esse aplicativo foi utilizado por nós com dados das crianças praticantes de Judô no projeto "PROCARIRI" da UFCG/Probex na cidade de Sumé, PB. 


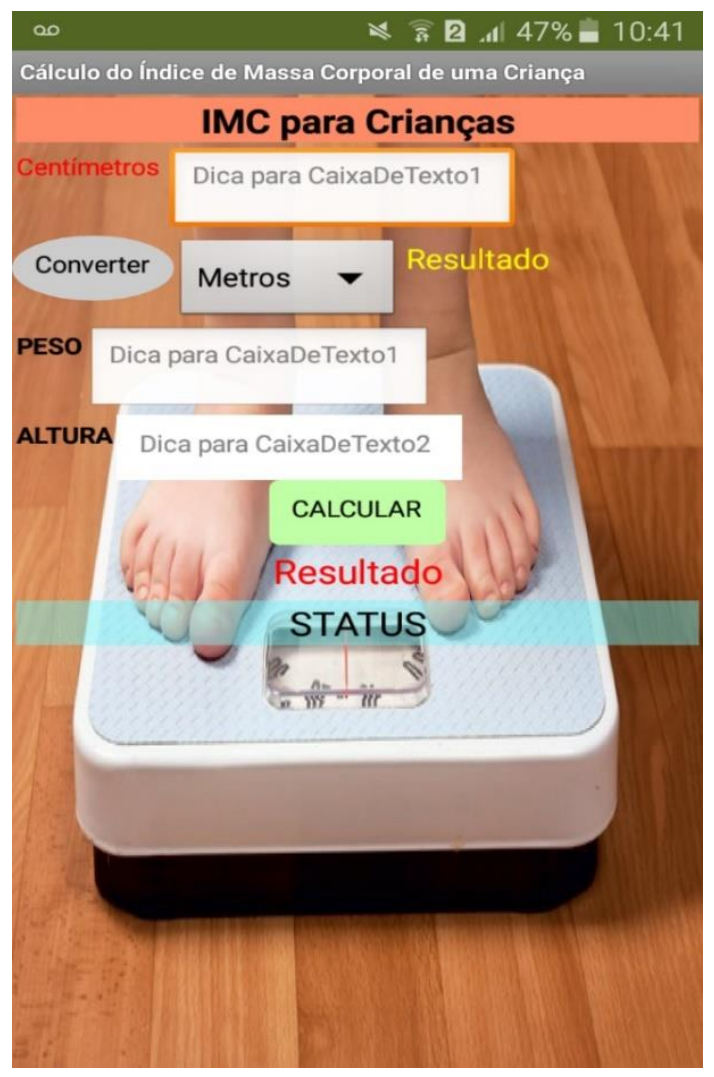

Fonte: Autoria própria (2019)

\section{Resultados e Discursões}

O aplicativo apresentado na Figura 01 foi aplicado junto ao "PROCARIRI" com 13 (treze) crianças que praticam o judô. A Figura 02 mostra os resultados obtidos por meio do aplicativo.

Figura 02 - Gráfico com os status correspondente a cada criança avaliada.

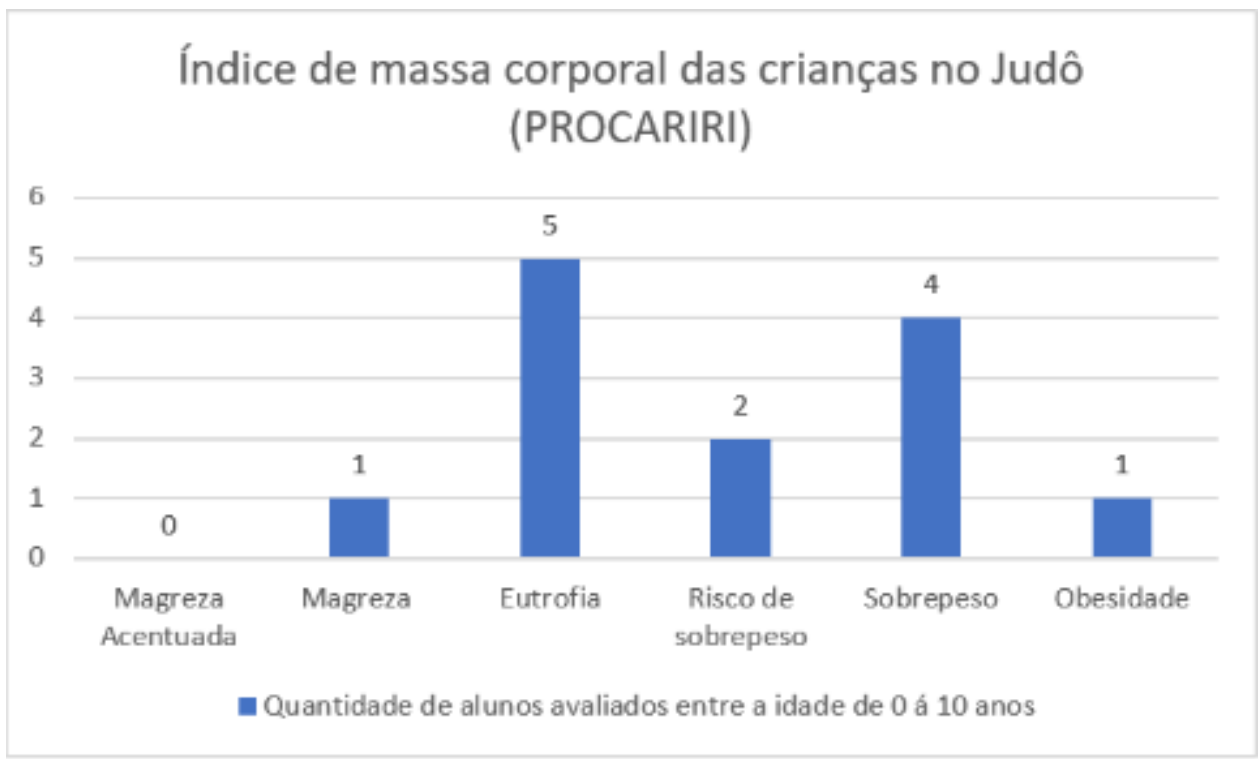


A partir dos resultados obtidos, percebe-se que mais de $40 \%$ das crianças estão acima do peso e $20 \%$ que estão correndo o risco de sobrepeso, diante disso, a pratica de exercício físico para essas crianças é de suma importância. Apenas 10\% estão abaixo do peso indicado e os demais apresentaram peso adequado e praticam o judô como uma atividade física contínua. Diante da obtenção destes resultados, os pais ou responsáveis pelas crianças devem procurar por um profissional da área, para melhor observação da massa corporal das crianças e tratar o peso e a saúde dos atletas.

O projeto de extensão de Inclusão Digital proporciona o ensino da lógica e da programação para celular através da linguagem de blocos. Com isto, uma professora da UFCG e seus alunos do curso de Engenharia de produção, no qual cursaram a disciplina de programação, ensinam aos alunos do ensino fundamental II e médio da rede estadual da cidade, a programar aplicativos de uso prático para celular, utilizando a ferramenta MIT APP Inventor (MIT, 2012).

O projeto de extensão "PROCARIRI”, disponibiliza na cidade de Sumé a prática do esporte para melhoramento físico, respeito, interação das crianças e dos adolescentes. Um fato positivo é a prática do esporte como melhoramento da saúde e desempenho corporal, diante disso, a procura pelo esporte na cidade de Sumé vem crescendo.

O aplicativo de IMC para crianças foi desenvolvido pela UFCG campus CDSA pensando nos instrutores de esportes para crianças e também nos profissionais da área de saúde, para facilitar a verificação dos cálculos de IMC durante as atividades. Diante da obtenção dos resultados, os instrutores de esportes podem fazer uma análise com base nos cálculos realizados pelo aplicativo e assim, indicar para as crianças melhorias de saúde e sua consequente consulta aos médicos adequados. Diante disso, com a utilização do aplicativo criado no projeto de extensão "Inclusão Digital" e sua utilização com as crianças do projeto "PROCARIRI", pôde-se detectar a importância do aplicativo, seu rápido e fácil funcionamento.

\section{Conclusão}

O objetivo do trabalho foi concluído, à medida que foi possível coletar dados reais com as crianças do projeto "PROCARIRI" (em execução na UFCG/CDSA) e inseri-los no Aplicativo “IMC para Crianças" criado no projeto "Inclusão Digital através da prática da lógica e da programação para alunos da rede pública da cidade de Sumé, PB” (também em execução na 
UFCG/CDSA) e verificar a sua utilização e funcionamento junto à comunidade da cidade. Desta maneira, instrutores de esportes da área de Judô ou instrutores de demais esportes praticados por crianças, e profissionais da área de saúde podem utilizá-lo e obter os resultados necessários durante o acompanhamento das crianças na realização das atividades físicas.

Diante do uso prático do aplicativo, pôde-se verificar que algumas crianças estão acima do peso mas que com o auxílio do aplicativo criado, puderam obter essa informação de maneira rápida, prática e individualizada, e assim compartilhar com os pais ou responsáveis para que tenham um acompanhamento de um profissional da área de saúde, em caso de necessidade.

\section{Referências bibliográficas}

Sardinha Evolution (2016) Atividade física/conheça os 6 benefícios da luta para sua saúde. Disponível em: <https://blog.sardinhaevolution.com.br/treinos/beneficios-da-luta-e-atividade-fisica/>. Acesso em: 08 de março de 2020.

CZEZACKI, ALINE (2017) Judô: Saiba mais sobre o esporte que proporciona benefícios à saúde física e mental. Disponivel em: <http://www.blog.saude.gov.br/index.php/materias-especiais/51454-judo-saiba-maissobre-o-esporte-que-proporciona-beneficios-a-saude-fisica-e-mental>. Acesso em: 08 de março de 2020.

FERREIRA, AFONSO (2017). O avanço da tecnologia e as transformações na sociedade. Disponível em: $<$ https://noticias.portaldaindustria.com.br/artigos/paulo-afonso-ferreira/o-avanco-da-tecnologia-e-astransformacoes-na-sociedade/>. Acesso em: 02 de fevereiro de 2020.

MACHADO, MELICIO (2018). Aplicativos para atividades físicas. Disponível em: <https://blog.laredo.com.br/aplicativos-para-atividades-fisicas/>. Acesso em: 07 de março de 2019.

GABELLINI, LARYSSA (2018). Conheça etapas do desenvolvimento de um aplicativo movel. Disponível em: <https://usemobile.com.br/conheca-as-etapas-do-desenvolvimento-de-um-aplicativo/_l>. Acesso em: 07 de março de 2019.

MIT - Massachussets Institute of Technology. 2012. App Inventor for Android. Disponível em: <http://appinventor.mit.edu/about-us> Acesso em: 20 de abril de 2019.

NOVA ESCOLA (2016). Blog tecnologia na educação. Disponível em: $<$ https://novaescola.org.br/conteudo/113/por-que-ensinar-programacao-na-escola $>$. Acesso em: 03 de fevereiro de 2020.

SIMULARE (2019). Inovação e tecnologia da educação. Avanços tecnológicos: como eles impactam positivamente a educação. Disponível em: <https://simulare.com.br/blog/avancos-tecnologicos-impacto-positivoeducacao/>. Acesso em: 15 de janeiro de 2019. 
